Received: 2016.11.11 Accepted: 2016.12.20 Published: 2017.03.21
Authors' Contribution: Study Design A Data Collection B Statistical Analysis C Data Interpretation D Manuscript Preparation E Literature Search F Funds Collection $G$

Corresponding Author: Source of support:

\section{Relationships Between Clinical, Self-Reported, and Donation Specific Outcomes: A Prospective Follow-up Study 10 Years After Kidney Donation}

\author{
ABCDE 1,2 Käthe B. Meyer \\ ADEG 1,2 Anders Hartmann \\ ACDE 1 Geir Mjøen \\ ADE 1,3 Marit Helen Andersen
}

1 Department of Transplantation, Oslo University Hospital, Rikshospitalet, Oslo,

Norway

2 Institute of Clinical Medicine University of Oslo, Oslo, Norway

3 Department of Health Science, University of Oslo, Oslo, Norway

Background: Long-term consequences of donor nephrectomy might be reduced kidney function, increased risk for cardiovascular disease, impaired quality of life, and fatigue. Few studies have investigated associations between clinical and self-reported outcomes in a long-term perspective. Thus, we aimed to investigate relationships between clinical, self-reported, and donation-specific outcomes in a nationwide cohort.

Material/Methods: We conducted a prospective follow-up study and assessed pre- and post-donation data from 202 donors who donated in 2001-2004. During 2012-2013, data on donors' self-reported (quality of life and fatigue) and donor-specific outcomes were collected. We performed linear regression for each component score of the generic instrument Short-Form, SF36v2, measuring quality of life, and the 5 domains of fatigue. Clinical parameters tested as independent variables were medical treatment of hyperlipidemia or hypertension, current smoking status, BMI, hemoglobin, and eGFR. Data were adjusted for age and gender.

Results: Approximately 10 years after donation, 67 donors were hypertensive and 54 donors had eGFR $<60 \mathrm{ml} / \mathrm{min} / 1.73 \mathrm{~m}$. Mean increase in plasma creatinine was $16.6 \mu \mathrm{mol} / \mathrm{l}(\mathrm{SD}=16.3)$. None of the clinical parameters were significant predictors for QoL. Female gender was significantly associated with general fatigue. There was a significant difference in perception of recognition from health personnel between donors with hypertension and donors without hypertension.

Conclusions: Our results show no associations between clinical and self-reported outcomes. However, we found a significant relationship between hypertension and donation-specific outcomes. Hypertension or reduced kidney function was identified in a minority of the donors. The increased risk for fatigue among female donors needs more investigation.

MeSH Keywords: $\quad$ Kidney Transplantation • Patient Outcome Assessment • Quality of Life • Time • Tissue and Organ Procurement

Abbreviations: $\quad$ BMI - body mass index; BP - blood pressure; eGFR - estimated glomerular filtration rate; ESRD - end stage renal disease; GF - general fatigue; HB - hemoglobin; LKD - live kidney donor; MCS - mental component score; MF - mental fatigue; MFI - multidimensional fatigue inventory; PCS - physical component score; PF - physical fatigue; PTH - parathyroid hormone; QoL - quality of life; RA - reduced activity; RM - reduced motivation; SF-36v2 - Short-Form 36v2; SPSS - Statistical Package for the Social Sciences

Full-text PDF: http://www.annalsoftransplantation.com/abstract/index/idArt/902330

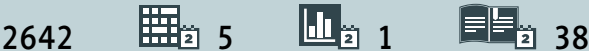




\section{Background}

Live donor kidney transplantation is considered to be the criterion standard treatment for patients with end-stage renal disease (ERSD). Globally, live kidney donation has increased by approximately $50 \%$ and is now an established treatment in most countries [1]. However, there has been stagnation and even a decline in some countries in Europe, Northern America, and Oceania [2,3]. This is also the case in Norway, where $40 \%$ of the kidney transplants were from live donors up to 2005 [4] but there has been a decline to $25 \%$ in 2015 . This may reflect some ambiguity concerning the use of live donors. Obviously, there is a need for long-term follow-up to provide precise knowledge with regard to long-term health, as a basis for safe expansion of live kidney donor (LKD) selection criteria, and to ensure qualified informed consent from prospective donors [5-7], as well as guidelines for long-term follow-up [8].

Over the years, a variety of long-term follow-up studies have been conducted. Age, gender, body mass index (BMI), blood pressure (BP), and time since donation have been associated with renal function [9-15], and recent studies suggest an increased risk for cardiovascular mortality $[16]$ and $\operatorname{ESRD}[17,18]$ in live donors compared to healthy non-donors. Furthermore, a recent prospective follow-up study assessed new-onset hypertension, finding a decrease in self-reported health outcomes and renal function 10 years after donation [19]. The authors suggest that the decrease was due to the donors' increased age. Similarly, a study by Sommerer et al. [20] raised concerns about risk for fatigue and reduced mental health in female donors. They also found an expected a decrease in renal function but no significant change in BP. However, none of these studies investigated if there was an association between selfreported health outcomes and renal function or other clinical parameters. To the best of our knowledge, no studies have actually investigated associations between long-term self-reported health and clinical variables. We therefore addressed a range of clinical parameters of potential relevance and their relationships with self-reported and donation-specific outcomes in a long-term prospective study.

\section{Material and Methods}

We invited 351 eligible Norwegian donors who donated a kidney at Oslo University Hospital, the Norwegian transplant center, in 2001-2004. The donors were invited by mail to participate in a 10-year follow-up study. Out of these, 217 were included. Data on self-reported health outcomes were presented in a previous report [21]. In the present study, long-term clinical data were also retrieved. Altogether, 202 out of 217 (93\%) patients who gave informed consent had clinical data retrieved about 10 years after donation. Figure 1 shows a diagram of the inclusion process.

\section{Data collection}

Baseline data were available in the Scandiatransplant Living Donor Registry database. Clinical variables at 10 -year followup were collected from the local nephrologists who performed the medical follow-up 10 years after donation. Donors' selfreported outcomes and donation-specific outcomes were collected in 2012-2013.

\section{Measurements}

Demographic characteristics included donors' age, gender, relationship to recipient, and years since donation.

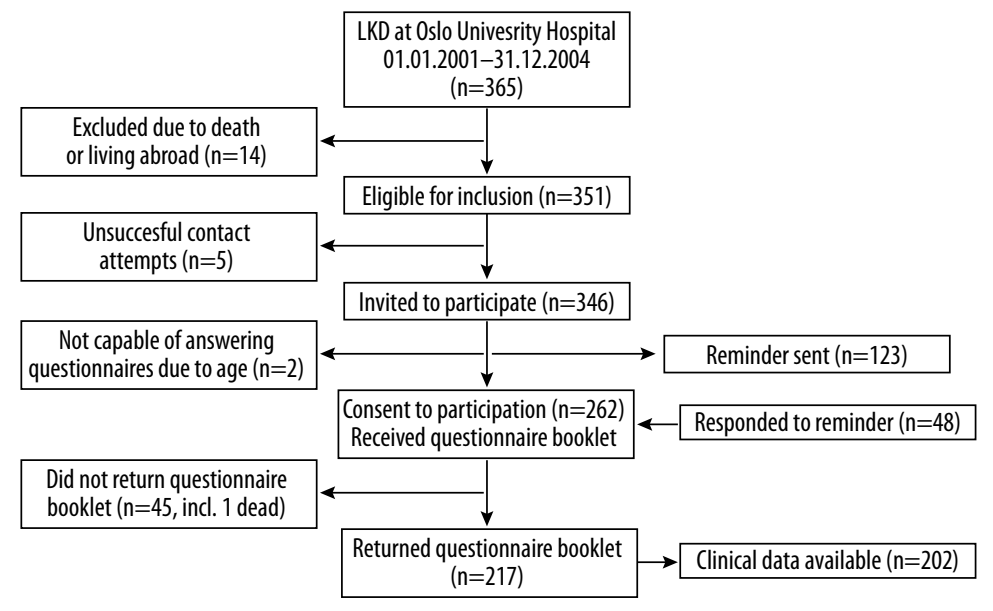

Figure 1. Flow diagram for inclusion. Inclusion criteria flow diagram. The diagram describes how the sample of living kidney donors (LKD) who completed the questionnaires $(\mathrm{N}=217)$ was derived from the total donors at Oslo University Hospital in 2001-2004. Clinical data were available for 202 donors. 
Clinical variables included weight, systolic and diastolic BP, use of antihypertensive drugs and statins, and smoking status. Blood tests included hemoglobin ( $\mathrm{HB})$, plasma creatinine, and parathyroid hormone (PTH). Estimated glomeruli filtration rate (eGFR) was calculated according to CKD-EPI equations. Urinary albumin/creatinine ratio was also measured. Changes in creatinine and $\mathrm{BMI}$ were estimated by comparing follow-up measures with baseline measures. PTH levels in the donors was assessed at 10 years and compared to reference values for the normal background population. Hypertension was defined as BP >140/90 or use of antihypertensive drugs.

Self-reported outcomes. The Short-Form (SF)-36v2 includes 36 items and evaluates 8 domains of functional health, which are summarized into physical (PCS) and mental health component scores (MCS). Each domain has a potential range of $0-100$. The component scores PCS and MCS are transformed to have a mean value of 50 and a standard deviation of 10 . Higher scores indicate better self-reported quality of life (QoL) [22]. Fatigue was assessed using the Multidimensional Fatigue Inventory (MFI), which includes 20 items covering 5 domains: general fatigue (GF), physical fatigue (PF), reduced activity (RA), reduced motivation (RM), and mental fatigue (MF). Each subscale has a potential range of 4-20; higher scores indicate more fatigue [23]. Both instruments were translated and validated into Norwegian [24,25].

Donor-specific factors. Donor-specific questions measured donation-specific factors; perceived recognition for going through the donation from family members and friends, and health care professionals; range 1-5 (from "not at all" to "a great extent"), expected recipient's health outcome (worse=1; as good as or better than expected=0), donor's assessment of the effect of donation on own health; range 1-5 (from "a great extent" to "not at all"), and if donor would have donated again (yes/no/unsure) [21].

\section{Statistical analysis}

Data were explored with descriptive analysis and are presented as frequencies, and measures of centrality and variance. The Wilcoxon Mann-Whitney $U$ test was performed to investigate differences in donation-specific outcomes between donors with eGFR < or $>60 \mathrm{ml} / \mathrm{min} / 1.73 \mathrm{~m}^{2}$, and donors with or without hypertension. Due to skewness in 3 of 5 domains in fatigue, we performed a logarithmic transformation on the domains GF, PF, and RA. To investigate potential associations between clinical and self-reported outcomes (SF36v2 and MFI), linear regression analysis was conducted. BMI, eGFR, medical treatment (antihypertensive drugs and statins), HB, and smoking status were independent variables, adjusted for age and gender. A $5 \%$ level of significance was considered statistically significant. All analyses were performed using the
Statistical Package for the Social Sciences version 21 (SPSS Inc., Chicago, IL, USA).

\section{Ethics}

The study was approved by the Regional Medical Research Committee for Health of South-East Norway (2011/2595 D) and by the hospital's data protection officer. An invitation letter, including information about the study, ensured confidentiality, and information about the possibility to withdraw from the study at any time was sent to eligible candidates. The candidates who returned the informed consent sheet were included in the study.

\section{Results}

\section{Demographics and relation to the recipient}

Median medical follow-up time was 11 years (range 6-15 years). Table 1 shows the characteristics of the donors. Mean age at medical follow-up was 60.6 years (range 34-89 years). The majority $(62.9 \%)$ were females and the most common relationship to the recipient was sibling (33.2\%), followed by parent $(25.7 \%)$.

\section{Clinical data}

Clinical data at medical follow-up are shown in Table 2. At follow-up, donors' mean systolic BP was $129.2 \mathrm{mmHg}(\mathrm{SD}=14.7)$ and diastolic BP was $78.5 \mathrm{mmHg}(\mathrm{SD}=7.8)$. One-third of the donors had hypertension $(n=67)$ and 52 used statins. Mean age of hypertensive donors was 63.7 years (SD 10.5). Mean eGFR was $68.1 \mathrm{ml} / \mathrm{min} / 1.73 \mathrm{~m}^{2}(\mathrm{SD}=14.0)$ and 54 donors had low eGFR ( $\left.<60 \mathrm{ml} / \mathrm{min} / 1.73 \mathrm{~m}^{2}\right)$; their mean age was 67.1 (SD=10.2). Mean change in creatinine was $16.6 \mu \mathrm{mol} / \mathrm{l}(\mathrm{SD}=16.3)$. The donors had a mean $\mathrm{BMI}$ of $26.5 \mathrm{~kg} / \mathrm{m}^{2}(\mathrm{SD}=3.7)$ and the mean change in $\mathrm{BMI}$ was $0.7(\mathrm{SD}=2.2)$.

\section{Self-reported outcomes}

Scores on QoL (SF-36v2) and fatigue (MFI) are presented in Table 3. The donors mainly scored high on PCS and MCS and low on all the domains of fatigue. As shown in Table 4, we found no significant association between clinical variables and PCS and MCS. In fatigue, there was a significant association between $\mathrm{BMI}$ and the domain RA, and between the domain GF and gender.

\section{Donation-specific factors}

Recognition from family or friends for being a donor was perceived by the majority of the donors, and two-thirds perceived 
Table 1. Demographics and relation to recipient.

\begin{tabular}{|c|c|c|c|}
\hline & $\mathbf{N}$ & Mean (SD) & Range \\
\hline Age at follow-up (years) & 202 & $60.6(10.6)$ & $34-89$ \\
\hline \multirow[t]{2}{*}{ Follow-up time after donation (years) } & & $11.3(1.5)$ & $6-15$ \\
\hline & \multicolumn{2}{|r|}{ (\%) } & \\
\hline \multicolumn{4}{|l|}{ Gender } \\
\hline Male & 75 & $(37.1)$ & \\
\hline Female & 127 & $(62.9)$ & \\
\hline \multicolumn{4}{|l|}{ Relationship to recipient } \\
\hline Parent & 52 & $(25.7)$ & \\
\hline Sibling & 67 & $(33.2)$ & \\
\hline Offspring & 21 & $(10.4)$ & \\
\hline Spouse & 36 & $(17.8)$ & \\
\hline Other & 26 & $(12.9)$ & \\
\hline
\end{tabular}

Descriptive analysis: continuous variables presented by mean and standard deviation (SD); nominal variables presented by frequency and percent (\%).

Table 2. Kidney donors; characteristics by clinical data at follow-up $(\mathrm{N}=202)$.

\begin{tabular}{|c|c|c|c|}
\hline & $\mathbf{N}$ & Mean & (SD) \\
\hline Systolic BP (mmHg) & 185 & 129.2 & $(14.7)$ \\
\hline Diastolic BP (mmHg) & 185 & 78.5 & (7.8) \\
\hline BMI & 163 & 26.5 & (3.7) \\
\hline Change in BMI & 163 & 0.7 & (2.2) \\
\hline Creatinine $(\mu \mathrm{mol} / \mathrm{L})$ & 202 & 91.6 & (18.4) \\
\hline Change in creatinine $(\mu \mathrm{mol} / \mathrm{L})$ & 200 & 16.6 & (16.3) \\
\hline eGFR $\left(\mathrm{ml} / \mathrm{min} / 1.73 \mathrm{~m}^{2}\right)$ & 201 & 68.1 & $(14.0)$ \\
\hline Hemoglobin (g/dl) & 197 & 14.3 & $(1.1)$ \\
\hline PTH (pmol/l) & 98 & 7.1 & $(4.2)$ \\
\hline Cholesterol (mmol/L) & 195 & 5.4 & (1.0) \\
\hline Triglycerides (mmol/L) & 159 & 1.4 & $(0.7)$ \\
\hline $\mathrm{HDL}(\mathrm{mmol} / \mathrm{L})$ & 181 & 1.6 & $(0.5)$ \\
\hline \multirow[t]{2}{*}{ LDL (mmol/L) } & 148 & 3.4 & (0.9) \\
\hline & & (\%) & \\
\hline Low eGFR & 54 & $(26.7)$ & \\
\hline Hypertension & 67 & $(33.2)$ & \\
\hline Proteinuria & 8 & $(3.7)$ & \\
\hline Microalbuminuria & 17 & (7.8) & \\
\hline Antihypertensive drugs & 64 & $(29.5)$ & \\
\hline Statins & 52 & $(25.7)$ & \\
\hline Current smoker & 26 & $(12.9)$ & \\
\hline Intercurrent diseases & 70 & $(34.7)$ & \\
\hline
\end{tabular}

Descriptive analysis: continuous variables presented by mean and standard deviation (SD); nominal variables presented by frequency and percent (\%). Hypertension was defined as BP>140/90 or antihypertensive drugs. Low eGFR was defined as $<60 \mathrm{ml} / \mathrm{min} / 1.73 \mathrm{~m}$. 
Table 3. Self-reported outcomes; Mean scores QoL (SF-36v2) and fatigue (MFI).

\begin{tabular}{|c|c|c|c|c|}
\hline & $\mathbf{N}$ & Mean & (SD) & Range \\
\hline Physical Component Score (PCS) & 182 & 53.52 & 8.74 & $21.98-65.51$ \\
\hline Mental Component Score (MCS) & 182 & 53.32 & 8.64 & $21.17-63.60$ \\
\hline General fatigue (GF) & 192 & 8.88 & 4.42 & $4-20$ \\
\hline Physical fatigue (PF) & 194 & 8.25 & 4.25 & $4-20$ \\
\hline Reduced activity (RA) & 196 & 8.38 & 4.11 & $4-20$ \\
\hline Reduced motivation (RM) & 193 & 7.31 & 3.14 & $4-19$ \\
\hline Mental fatigue (MF) & 197 & 8.03 & 3.57 & $4-19$ \\
\hline
\end{tabular}

Descriptive analysis: continuous variables presented by mean and standard deviation (SD); SF-36v2: each component score has a theoretical range of 0-100; MFI: each subscale has a theoretical range of 4-20; higher scores indicate more fatigue.

Table 4. Association between QoL and fatigue and clinical variables, gender and age.

\begin{tabular}{|c|c|c|c|c|c|c|c|c|}
\hline & & PCS & MCS & $\mathrm{GF}^{\mathrm{a}}$ & $\mathrm{PF}^{\mathrm{a}}$ & $\mathrm{RA}^{\mathrm{a}}$ & RM & MF \\
\hline eGFR & $\begin{array}{c}\text { B } \\
\text { (St.error) }\end{array}$ & $\begin{array}{c}0.04 \\
(0.07)\end{array}$ & $\begin{array}{l}-0.07 \\
(0.07)\end{array}$ & $\begin{array}{c}0.01 \\
(0.00)\end{array}$ & $\begin{array}{l}0.00 \\
0.00\end{array}$ & $\begin{array}{c}0.00 \\
(0.00)\end{array}$ & $\begin{array}{c}0.04 \\
(0.03)\end{array}$ & $\begin{array}{c}0.01 \\
(0.03)\end{array}$ \\
\hline BMI & $\begin{array}{c}\text { B } \\
\text { (St.error) }\end{array}$ & $\begin{array}{c}-0.40 \\
0.23\end{array}$ & $\begin{array}{l}-0.01 \\
(0.22)\end{array}$ & $\begin{array}{c}0.02 \\
(0.01)\end{array}$ & $\begin{array}{l}0.04^{* *} \\
(0.01)\end{array}$ & $\begin{array}{c}0.02 \\
(0.01)\end{array}$ & $\begin{array}{c}0.05 \\
(0.08)\end{array}$ & $\begin{array}{c}0.04 \\
(0.09)\end{array}$ \\
\hline $\begin{array}{l}\text { Use of } \\
\text { antihypertensives } \\
\text { and/or statins }\end{array}$ & $\begin{array}{c}\text { B } \\
\text { (St.error) }\end{array}$ & $\begin{array}{c}0.16 \\
(1.25)\end{array}$ & $\begin{array}{c}0.55 \\
(1.24)\end{array}$ & $\begin{array}{c}0.01 \\
(0.07)\end{array}$ & $\begin{array}{c}0.06 \\
(0.06)\end{array}$ & $\begin{array}{c}0.01 \\
(0.06)\end{array}$ & $\begin{array}{c}0.16 \\
(0.44)\end{array}$ & $\begin{array}{l}-0.17 \\
(0.47)\end{array}$ \\
\hline Hemoglobin & $\begin{array}{c}\text { B } \\
\text { (St.error) }\end{array}$ & $\begin{array}{c}0.55 \\
(0.94)\end{array}$ & $\begin{array}{c}0.68 \\
(0.93)\end{array}$ & $\begin{array}{c}0.02 \\
(0.05)\end{array}$ & $\begin{array}{l}-0.05 \\
(0.05)\end{array}$ & $\begin{array}{l}-0.06 \\
(0.05)\end{array}$ & $\begin{array}{c}0.26 \\
(0.32)\end{array}$ & $\begin{array}{l}-0.06 \\
(0.35)\end{array}$ \\
\hline Smoking & $\begin{array}{c}\text { B } \\
\text { (St.error) }\end{array}$ & $\begin{array}{l}-1.14 \\
(2.42)\end{array}$ & $\begin{array}{l}-1.57 \\
(2.40)\end{array}$ & $\begin{array}{c}0.00 \\
(0.14)\end{array}$ & $\begin{array}{l}-0.05 \\
(0.12)\end{array}$ & $\begin{array}{l}-0.06 \\
(0.13)\end{array}$ & $\begin{array}{l}-1,45 \\
(0.88)\end{array}$ & $\begin{array}{l}-1.64 \\
(0.95)\end{array}$ \\
\hline Gender & $\begin{array}{c}\text { B } \\
\text { (St.error) }\end{array}$ & $\begin{array}{l}-2.57 \\
(1.96)\end{array}$ & $\begin{array}{l}-2.81 \\
(1.94)\end{array}$ & $\begin{array}{l}0.23^{*} \\
(0.11)\end{array}$ & $\begin{array}{c}0.17 \\
(0.10)\end{array}$ & $\begin{array}{c}0.11 \\
(0.10)\end{array}$ & $\begin{array}{c}1.27 \\
(0.70)\end{array}$ & $\begin{array}{c}0.42 \\
(0.76)\end{array}$ \\
\hline $\begin{array}{l}\text { Age (at medical } \\
\text { follow-up) }\end{array}$ & $\begin{array}{c}\text { B } \\
\text { (St.error) }\end{array}$ & $\begin{array}{l}-0.13 \\
(0.10)\end{array}$ & $\begin{array}{l}-0.01 \\
(0.10)\end{array}$ & $\begin{array}{l}0.00 \\
(0.01)\end{array}$ & $\begin{array}{l}0.00 \\
(0.01)\end{array}$ & $\begin{array}{l}0.00 \\
(0.01)\end{array}$ & $\begin{array}{c}0.04 \\
(0.04)\end{array}$ & $\begin{array}{c}0.03 \\
(0.04)\end{array}$ \\
\hline
\end{tabular}

Linear regression: each domain was analyzed separately; PCS - physical component score; MCS - mental component score; GF general fatigue; PF - physical fatigue; RA - reduced activity; RM - reduced motivation; MF - mental fatigue; B - the regression coefficient.

${ }^{a}$ Logaritmic transformation; ${ }^{*} p<0.05 ;{ }^{* *} p<0.01$.

recognition to a great extent or to some extent from health personnel, as shown in Table 5. Donors with hypertension perceived significantly more recognition from health personnel than those without hypertension. Nearly all donors would donate again if possible, but significantly fewer donors with hypertension felt this way. Less than $20 \%$ perceived the donation to be harmful to their own health. The recipients' health was described as expected or better than expected by the majority $(70.8 \%)$ of the donors.

\section{Discussion}

This long-term follow-up study shows that the majority of the donors have good outcomes, both clinical and self-reported at approximately 10 years after donation. The results are in line with several follow-up studies performed over the years $[5,11,14,19,20]$.

This is the first study to investigate the association between clinical outcomes and donors' perception of their own health and donation-specific factors. One particular aspect of our study was the association between clinical outcomes and the donors' perception of recognition for their donation. In our previous study [21], significantly fewer donors perceived recognition from health personnel than from family and friends. Thus, it is interesting that the hypertensive donors in the current study perceived significantly more recognition from health personnel than did normotensive LKD, while perception of recognition 
Table 5. Perception of recognition and self-evaluation of health in donors with low GFR or hypertension.

\begin{tabular}{|c|c|c|c|c|c|c|c|c|}
\hline & \multicolumn{2}{|c|}{$\begin{array}{c}\text { All } \\
(\mathrm{N}=202)\end{array}$} & \multicolumn{3}{|c|}{$\begin{array}{c}\text { eGFR }<60 \mathrm{ml} / \mathrm{min} / 1.73 \mathrm{~m}^{2} \\
(\mathrm{~N}=54)\end{array}$} & \multicolumn{3}{|c|}{$\begin{array}{l}\text { Hypertension } \\
\quad(\mathrm{N}=67)\end{array}$} \\
\hline & $\mathbf{n}$ & $(\%)$ & $\mathbf{n}$ & $(\%)$ & $\mathbf{P}^{*}$ & $\mathbf{n}$ & $(\%)$ & $P^{* *}$ \\
\hline Recognition from health personnel & & & & & 0.71 & & & 0.02 \\
\hline To a great extent & 74 & $(36.6)$ & 20 & $(37.0)$ & & 29 & $(43.3)$ & \\
\hline To some extent & 54 & $(26.7)$ & 15 & $(27.8)$ & & 13 & $(19.4)$ & \\
\hline To a little extent & 30 & $(14.9)$ & 9 & $(16.7)$ & & 9 & $(13.4)$ & \\
\hline Not at all & 25 & $(12.4)$ & 4 & $(7.4)$ & & 6 & $(9.0)$ & \\
\hline Unsure & 16 & (7.9) & 4 & $(7.4)$ & & 9 & $(13.4)$ & \\
\hline Recognition from family/friends & & & & & 0.24 & & & 0.71 \\
\hline To a great extent & 128 & $(63.4)$ & 34 & $(63.0)$ & & 40 & $(59.7)$ & \\
\hline To some extent & 47 & $(23.3)$ & 13 & $(24.1)$ & & 18 & $(26.9)$ & \\
\hline To a little extent & 15 & $(7.4)$ & 2 & $(3.7)$ & & 3 & $(4.5)$ & \\
\hline Not at all & 1 & $(0.5)$ & 0 & (0) & & 1 & $(1.5)$ & \\
\hline Unsure & 7 & (3.5) & 4 & (7.4) & & 4 & $(6.0)$ & \\
\hline Donation harmful to own health & & & & & 0.21 & & & 0.38 \\
\hline To a great extent & 1 & $(0.5)$ & 0 & $(0)$ & & 0 & (0) & \\
\hline To some extent & 11 & $(5.4)$ & 2 & (3.7) & & 3 & $(4.5)$ & \\
\hline To a little extent & 27 & $(13.4)$ & 6 & $(11.1)$ & & 7 & $(10.4)$ & \\
\hline Not at all & 150 & $(74.3)$ & 43 & $(79.6)$ & & 53 & $(79.1)$ & \\
\hline Unsure & 11 & $(5.4)$ & 2 & (3.7) & & 4 & $(6.0)$ & \\
\hline Would have donated again & & & & & 0.43 & & & 0.01 \\
\hline Yes & 189 & (94) & 52 & (96) & & 58 & $(86.6)$ & \\
\hline No & 6 & (3) & 0 & (0) & & 4 & $(6.0)$ & \\
\hline Unsure & 6 & (3) & 2 & (4) & & 4 & $(6.0)$ & \\
\hline
\end{tabular}

Non-parametric independent samples Wilcoxon Mann-Whitney U Test; * p-value between donors with eGFR $<$ or $>60 \mathrm{ml} / \mathrm{min} / 1.73 \mathrm{~m}$; ${ }^{* *} p$-value between donors with or without hypertension; low GFR: $\left\langle 60 \mathrm{ml} / \mathrm{min} / 1.73 \mathrm{~m}^{2}\right.$; hypertension: BP $>140 / 90$ or antihypertensive drugs.

from family and friends did not differ. One explanation may be that LKD who develop hypertension might be followed more closely and therefore receive more attention from health professionals than did the normotensive donors. However, we do not know if the frequency of medical follow-up differs between the groups. Another noteworthy finding was that even though only a minority claimed that the donation had been harmful to own health, 4 of the 6 LKD who retrospectively were reluctant to donate were in the hypertensive group. This might be in line with our previous report [21], which found that 3 donors both regretted donation and perceived that the donation had harmed their health. None of our donors were in need of kidney replacement treatment; hence, it seems as if being dependent on antihypertensive agents might be more burdensome than symptom-free reduced kidney function. Being dependent of taking antihypertensive agents may give a feeling of reduced health as a consequence of the donation, which again can affect the retrospective willingness to donate. Still, in contrast to a previous study comparing QoL between kidney recipients and patients in dialysis [26], we did not find any association between hypertension and self-reported health QoL. The donors may be employing beneficial denial and avoidance strategies, because being hypertensive is a situation out of their control [27], and this might explain the incongruence 
in our findings. In the present study, one-third of the donors were treated by antihypertensive agents. Hypertension and use of antihypertensive drugs after donation has been shown in other studies; however, the incidence varies $[9,14,19,28]$, and in 1 study nearly half of the donors were on antihypertensive agents or had undiagnosed hypertension at a mean follow-up time of 14 years [14]. Elderly donors might be more hypertensive than younger ones [19]; however, in our cohort the share of LKD at age 67 years or older who were treated for hypertension was lower than in the Norwegian population in the same age group [29], at $43.9 \%$ vs. $50 \%$, respectively. The donors in the cohort studies by Kasiske [28] and Janki [19] had a lower mean age than the donors in our cohort, which may explain the lower incident of hypertension. Most of our donors were younger than 67 years, and in the age group 45 to 66 years, $31 \%$ of the LKD were treated with antihypertensive drugs compared to $21 \%$ of the Norwegian general population in the same age group [29]. It appears that the incidence of hypertension is somewhat higher in the donors when compared to the background population. Although a higher incidence of hypertension in donors may possibly be explained by the donation per se, it may also be explained by the regular scheduled visits during long-term follow-up with a higher likelihood of detection of hypertension. These results indicate the importance of long-term follow-up in order to monitor BP and assure that hypertensive treatment will be initiated when needed.

Another result that promotes long-term follow-up is that even though no donors were in treatment for reduced kidney function, a minority of the donors had low eGFR $\left(<60 \mathrm{ml} / \mathrm{min} / 1.73 \mathrm{~m}^{2}\right)$ at 10 years after donation. This result corresponds with results from other studies $[14,15,19,28,30]$. However, previous studies indicate both an increase and a decrease in GFR after donation $[14,15,28]$. Fehrman-Ekholm et al. [14] suggested that GFR increases in the first years after donation, and then stabilizes before a decrease in GFR starts. If this is the case, the LKD in the current study might be in the stable phase at approximately 10 years post-donation, and we might see a decrease after 15 or 20 years after donation. In contrast, Fournier et al. [13] found no decrease in kidney function 30 years after donation. The uncertainty of the course of GFR after donation supports the need for long-term follow-up. However, even if the policy in Norway is to follow the donors at 5-year intervals, not all Norwegian donors have a medical follow-up at 10 years [21].

Another significant finding was the association between gender and general fatigue. Even though the evidence of gender differences in fatigue is inconsistent [31-34], female gender has previously been associated with fatigue in $\operatorname{LKD}[20,21]$. In a previous report, we reported that female donors scored significantly higher than male donors on 3 out of 5 domains of fatigue [21]. Congruently, Sommerer et al. [20] found that female donors scored lower on MCS in QoL, and that middle-aged female donors scored higher on 2 out of 5 domains in fatigue compared to the German general population. The findings in the present study and in the previous studies seem to strengthen the notion that female donors might be more exposed to fatigue than male donors, and may need to be followed more closely after donation. The knowledge gap on gender differences in fatigue and live donation indicates a need for more research on this topic.

Even though we did not discover any association between gender and the 2 component scores PCS and MCS in this study, we did find a gender difference in 4 domains of QoL in our previous study [21]. This is similar to the results of Ay et al. [35], who compared QoL in recipients, donors, and a control group, and reported that male donors scored higher on PCS and MCS than female donors at 9 months after donation.

The body of long-term research on live kidney donation has a variation in design, including retrospective, prospective, or matched control groups. Additionally, time span varies from less than 5 years to nearly 50 years after donation, and there is a huge difference in sample sizes; from less than 100 LKD up to several thousand $[9,10,13,17,18,36,37]$. The dissimilarity makes it difficult to compare results. One of the strengths of our study was that median follow-up time was 11 years, with a limited time span. This may give more precise information about long-term health after donation. Other strengths were the sample size of 202 donors and that this was a nationwide study.

Our findings should be interpreted cautiously. This study was a follow-up of a previous study on quality of life in kidney donors. When planning the original study, we did not perform any power calculation for evaluating potential associations between blood pressure, renal function, and quality of life measures. Accordingly, our mainly negative findings could be explained by lack of statistical power. The design did not allow for comparison with healthy controls, which might be another limitation. However, studies using control groups have limitations as well, and it is difficult to find appropriate control groups [38].

\section{Conclusions}

Our results show no associations between clinical and self-reported outcomes. However, we found a significant relationship between hypertension and donor-specific factors. Hypertension and reduced kidney function were identified in a minority of the donors. Hypertension may affect the self-perception of health and retrospective willingness to donate.

Long-term follow-up appears to be mandatory for monitoring of blood pressure and kidney function. The increased risk for fatigue among female donors needs more investigation. 


\section{Competing interests}

The authors of this manuscript have no conflicts of interest to disclose.

\section{References:}

1. Horvat LD, Shariff SZ, Garg AX, Donor Nephrectomy Outcomes Research (DONOR) Network: Global trends in the rates of living kidney donation. Kidney Int, 2009; 75: 1088-98

2. Reese PP, Boudville N, Garg AX: Living kidney donation: outcomes, ethics, and uncertainty. Lancet, 2015; 385: 2003-13

3. Rodrigue JR, Schold JD, Mandelbrot DA: The decline in living kidney donation in the United States: random variation or cause for concern? Transplantation, 2013; 96: 767-73

4. Witczak BJ, Leivestad T, Line PD et al: Experience from an active preemptive kidney transplantation program -809 cases revisited. Transplantation, 2009; 88: 672-77

5. Soneji ND, Vyas J, Papalois VE: Long-term donor outcomes after living kidney donation. Exp Clin Transplant, 2008; 6: 215-23

6. Tong A, Chapman JR, Wong $G$ et al: The motivations and experiences of living kidney donors: a thematic synthesis. Am J Kidney Dis, 2012; 60: 15-26

7. Gordon EJ: Informed consent for living donation: A review of key empirical studies, ethical challenges and future research. Am J Transplant, 2012; 12(9): 2273-80

8. Lennerling A, Forsberg A: Donors self-reported experiences of live kidney donation - a prospective study. J Ren Care, 2012; 38: 207-12

9. Mjoen G, Midtvedt K, Holme I et al: One- and five-year follow-ups on blood pressure and renal function in kidney donors. Transpl Int, 2011; 24: 73-77

10. Mjoen G, Oyen O, Midtvedt $\mathrm{K}$ et al: Age, gender, and body mass index are associated with renal function after kidney donation. Clin Transplant, 2011; 25: $579-83$

11. Berger JC, Muzaale AD, James N et al: Living kidney donors ages 70 and older: Recipient and donor outcomes. Clin J Am Soc Nephrol, 2011; 6: 2887-93

12. Dols LF, Kok NF, Roodnat JI et al: Living kidney donors: Impact of age on long-term safety. Am J Transplant, 2011; 11: 737-42

13. Fournier C, Pallet N, Cherqaoui Z et al: Very long-term follow-up of living kidney donors. Transpl Int, 2012; 25: 385-90

14. Fehrman-Ekholm I, Kvarnstrom N, Softeland JM et al: Post-nephrectomy development of renal function in living kidney donors: A cross-sectional retrospective study. Nephrol Dial Transplant, 2011; 26: 2377-81

15. Ibrahim HN, Foley R, Tan L et al: Long-term consequences of kidney donation. N Engl J Med, 2009; 360: 459-69

16. Mjoen G, Reisaeter A, Hallan S et al: Overall and cardiovascular mortality in Norwegian kidney donors compared to the background population. Nephrol Dial Transplant, 2012; 27: 443-47

17. Mjoen G, Hallan S, Hartmann A et al: Long-term risks for kidney donors. Kidney Int, 2014; 86: 162-67

18. Muzaale $A D$, Massie $A B$, Wang $M C$ et al: Risk of end-stage renal disease following live kidney donation. JAMA, 2014; 311: 579-86

19. Janki S, Klop KW, Dooper IM et al: More than a decade after live donor nephrectomy: A prospective cohort study. Transpl Int, 2015; 28: 1268-75

20. Sommerer C, Feuerstein D, Dikow R et al: Psychosocial and physical outcome following kidney donation-a retrospective analysis. Transpl Int, 2015; 28: $416-28$

\section{Acknowledgement}

We thank the local nephrologists who provided data on clinical parameters and, in particular, all the donors who participated in the cross-sectional study.

21. Meyer K, Wahl AK, Bjork IT et al: Long-term, self-reported health outcomes in kidney donors. BMC Nephrol, 2016; 17: 8

22. Ware JE Jr., Sherbourne CD: The MOS 36-item short-form health survey (SF-36). I. Conceptual framework and item selection. Med Care, 1992; 30: 473-83

23. Smets EM, Garssen B, Bonke B, De Haes JC: The Multidimensional Fatigue Inventory (MFI) psychometric qualities of an instrument to assess fatigue. J Psychosom Res, 1995; 39: 315-25

24. Loge JH, Kaasa S: Short form 36 (SF-36) health survey: Normative data from the general Norwegian population. Scand J Soc Med, 1998; 26: 250-58

25. Le Gal M, Mainguy Y, Le Lay $\mathrm{K}$ et al: Linguistic validation of six patient-reported outcomes instruments into 12 languages for patients with fibromyalgia. Joint Bone Spine, 2010; 77: 165-70

26. Czyzewski L, Sanko-Resmer J, Wyzgal J, Kurowski A: Assessment of healthrelated quality of life of patients after kidney transplantation in comparison with hemodialysis and peritoneal dialysis. Ann Transplant, 2014; 19 576-85

27. Nowak Z, Wankowicz Z, Laudanski K: Denial defense mechanism in dialyzed patients. Med Sci Monit, 2015; 21: 1798-805

28. Kasiske BL, Anderson-Haag T, Israni AK et al: A prospective controlled study of living kidney donors: Three-year follow-up. Am J Kidney Dis, 2015; 66: $114-24$

29. Norway S: Health, care and social relations, survey on living conditions. Statistics Norway 2016. http://www.ssb.no/statistikkbanken. Accessed 28.06.2016

30. Young $\mathrm{A}$, Hodsman $\mathrm{AB}$, Boudville $\mathrm{N}$ et al: Bone and mineral metabolism and fibroblast growth factor 23 levels after kidney donation. Am J Kidney Dis, 2012; 59: 761-69

31. Boter $H$, Manty $M$, Hansen $A M$ et al: Self-reported fatigue and physical function in late mid-life. J Rehabil Med, 2014; 46: 684-90

32. Hagelin CL, Wengstrom Y, Runesdotter S, Furst CJ: The psychometric properties of the Swedish Multidimensional Fatigue Inventory MFI-20 in four different populations. Acta Oncol, 2007; 46: 97-104

33. Watt T, Groenvold M, Bjorner JB et al: Fatigue in the Danish general population. Influence of sociodemographic factors and disease. J Epidemiol Community Health, 2000; 54: 827-33

34. Schwarz R, Krauss O, Hinz A: Fatigue in the general population. Onkologie, 2003; 26: 140-44

35. Ay N, Anil M, Alp V et al: Evaluation of quality of life early and late after kidney transplantation. Ann Transplant, 2015; 20: 493-99

36. Fehrman-Ekholm I, Kvarnstrom N, Softeland JM et al: Post-nephrectomy development of renal function in living kidney donors: A cross-sectional retrospective study. Nephrol Dial Transplant, 2011; 26: 2377-81

37. Dols LF, ljzermans JN, Wentink $N$ et al: Long-term follow-up of a randomized trial comparing laparoscopic and mini-incision open live donor nephrectomy. Am J Transplant, 2010; 10: 2481-87

38. Matas AJ, Hays RE, Ibrahim HN: Long-term non-ESRD risks after living kidney donation. Am J Transplant, 2016 [Epub ahead of print] 